\title{
Fronterización y concertaciones transfronterizas en América Latina
}

\section{Borders and Latin American cross-border agreements}

Recibido el 29 de octubre de 2020. Aceptado el 23 de abril de 2021. Publicado el 30 de abril de 2021.

* Autor para correspondencia: Haroldo Dilla Alfonso. Correo electrónico: hdillaalfonso@gmail.com

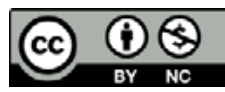

Esta obra está protegida bajo una Licencia Creative Commons Atribución-NoComercial 4.0 Internacional.

\begin{abstract}
Haroldo Dilla Alfonso ${ }^{a^{*}}$ (D) https://orcid.org/0000-0001-7744-8362 Camila Contreras Vera ${ }^{a}$ (D) https://orcid.org/0000-0002-1958-3424
\end{abstract}

${ }^{\text {a }}$ Universidad Arturo Prat, Instituto de Estudios Internacionales, Santiago, Chile, correo electrónico: hdillaalfonso@gmail.com, camila.contreras.v@gmail.com

\section{Resumen}

Este artículo discute la emergencia de un campo de estudios sobre las concertaciones transfronterizas en América Latina como un rasgo positivo en favor de la construcción de una teoría crítica de las fronteras latinoamericanas, pero al mismo tiempo lastrado en términos heurísticos por sus dependencias teóricas y metodológicas al mainstream de los estudios europeos y norteamericanos. Se propone una aproximación teórica que, sin obviar la riqueza acumulada en estos estudios, tome en cuenta las características de la fronterización neoliberal en América Latina y la realidad de sus experiencias de concertaciones. En este sentido se analizan varios casos a partir de una tipología preliminar basada en los orígenes institucionales/escalares de ellos.

Palabras clave: fronteras, concertaciones transfronterizas, América Latina.

\section{Abstract}

This article discusses the emergence of a field of studies on cross-border agreements in Latin America as a positive feature in favor of the construction of a critical theory of Latin American borders, but at the same time weighed down in heuristic terms by its theoretical and methodological dependences to the mainstream of European and North American studies. A theoretical approach is proposed that, without ignoring the stock accumulated in these studies, considers the characteristics of the neoliberal bordering in Latin America and the reality of its experiences of agreements. In this sense, several cases are analyzed from a preliminary typology based on their institutional/scalar origins.

Keywords: borderlands, cross-border agreements, Latin America.

CÓMO CITAR: Dilla Alfonso, H. \& Contreras Vera, C. (2021). Fronterización y concertaciones transfronterizas en América Latina [Borders and Latin American cross-border agreements]. Estudios Fronterizos, 22, e069. https://doi.org/10.21670/ref. 2106069 


\section{Introducción}

Uno de los datos más relevantes de los estudios sobre las fronteras internacionales en América Latina es la multiplicación de los análisis sobre aquellas relaciones transfronterizas remisibles a lo que se ha denominado paradiplomacia - tal y como tempranamente las definió Soldatos, $1993^{1}$ — y que aquí llamaremos concertaciones transfronterizas. ${ }^{2}$ Así, en los últimos años han aparecido en nuestro continente al menos una decena de libros dedicados exclusiva o predominantemente al tema (Barajas et al., 2015; González et al., 2016; Molano, 2016; Moya, 2012; Oddone \& Ramos, 2018a; Oddone et al., 2016; Rhi-Sausi \& Oddone, 2013; Soto \& Ramírez, 2014, para citar algunos) y tanto las revistas especializadas como las reuniones académicas han tenido que crear espacios para la discusión acerca de cómo y para qué los actores fronterizos se ponen de acuerdo para crear espacios nuevos de gestión.

Todo ello constituye un aporte a los estudios fronterizos y territoriales en nuestro continente. Digamos que, entre otras virtudes, estos estudios han conseguido rebasar aspectos tradicionales de la geopolítica que habían primado usualmente en el tema e incorporar a sus análisis el accionar de una variedad mayor de actores y situaciones que lo que ofrecían los estudios precedentes anclados en visiones centralistas. Esto provee a los estudios fronterizos de una infinidad de estudios de casos susceptibles de análisis comparados más intensos, y tributarios a la conformación de una teoría propia sobre el tema. En cualquier caso, fomenta un debate del que este artículo aspira a ser parte.

Los logros alcanzados, sin embargo, no omiten una dificultad heurística mayor. Una parte considerable de estos estudios — diríamos que su mainstream— ha estado fuertemente influida por los dos paradigmas mundiales en los estudios de frontera: la Unión Europea y la frontera que comparten México y Estados Unidos. Desde la primera, los especialistas latinoamericanos recibieron la incidencia directa en 20072012 del Programa Fronteras Abiertas (Rhi-Sausi \& Conato, 2009) del Centro Studi Politica Internazionale (Cespi), cuya finalidad era difundir la experiencia europea como "marco teórico referencial" y para lo cual contaban con financiamientos disponibles para investigaciones, entrenamientos, publicaciones y asesoramientos a proyectos en América Central y del Sur. Desde el ámbito norteamericano, los estudios sobre cooperación transfronteriza han contado con una sólida red de instituciones académicas en ambos lados de la frontera que han generado una interesante producción intelectual, algunas de cuyas parcelas aún comparten la euforia de la convergencia y la hibridación que marcó la década de 1990.

\footnotetext{
1 Se debe a Soldatos (1993) una de las definiciones seminales más amplia sobre el tema: “(...) toda actividad internacional directa realizada por actores subnacionales (regiones, unidades federadas, comunidades urbanas, ciudades) apoyando, complementando, corrigiendo, duplicando o retando la diplomacia de los estados nacionales" (p. 48).

${ }^{2}$ En este punto es imprescindible una aclaración conceptual. Aquí hablamos de concertaciones transfronterizas cuando se producen acercamientos regulares y se adoptan acuerdos para el funcionamiento presente o futuro de territorios distinguibles por la densidad de flujos y relaciones entre comunidades ubicadas en torno a límites internacionales. Aunque estas concertaciones pueden estar organizadas desde los niveles nacionales, su sello imprescindible es el involucramiento activo de actores locales. Esta dimensión territorial/local es la que marca la diferencia crucial entre una concertación transnacional y otra transfronteriza. Desafortunadamente, es usual que, en los estudios especializados sobre el tema de la paradiplomacia, ambas situaciones sean confundidas y se denomine como transfronterizo simplemente a todo aquello que cruza fronteras.
} 
Esto no es un problema en sí. Las relaciones simbióticas con campos y escuelas de pensamiento preexistentes son constitutivas de la investigación científica, y por ello no es extraño que estas influencias hayan existido. Por otra parte, es conveniente establecer estas relaciones con estos dos espacios académicos que han conseguido notables avances teóricos y metodológicos en los estudios sobre el tema. El inconveniente heurístico reside en que en ocasiones esta relación opera sobre una adopción acrítica en desmedro de la propia producción intelectual acumulada en el continente. Y, desde aquí, se ha generado un aparato conceptual que, sin obviar sus méritos mencionados, se apoya frecuentemente en metáforas de parco valor heurístico. En consecuencia, la emergencia de una "voz consensuada y relativamente homogénea" que Oddone y Ramos (2018b, p. 279) percibían como antesala de una comunidad epistémica, ${ }^{3}$ no es fundamentalmente el resultado de una crítica teórica sobre la realidad concreta y sobre el stock cognoscitivo acumulado, sino, más bien, la anteposición a esa realidad de cánones y paradigmas teóricos consagrados en otras latitudes.

Solo para ilustrar la afirmación anterior, vale la pena recrear un documento emitido por la Cepal —aunque no asumido como posición oficial— y firmado por cuatro prestigiosos académicos latinoamericanos (Oddone et al., 2016). Bajo el sugerente título de "Pactos territoriales en la construcción de regiones transfronterizas: por una mayor integración a múltiples niveles", las fronteras son definidas como "espacios interestatales" cuyas relaciones se constituyen "(...) en función del grado de permeabilidad de sus límites, del nivel de autonomía de los gobiernos subnacionales y los procesos de descentralización en curso, del peso de la política nacional y de los acuerdos interjurisdiccionales, de las iniciativas regionales que promuevan la integración o de la rigidez de la agenda de la seguridad internacional" (p. 19). Se reconoce aquí la existencia de espacios informales, pero, no obstante, recomienda que sean "(...) formalizados y desnaturalizados" (p. 12). El "bien común” se conseguiría de la mano de estados "(...) garantes de los derechos progresivos" (p. 12) y de proyectos de integración, apoyados en una mayor conectividad física que genera "(...) las condiciones necesarias para atraer inversiones y reducir las asimetrías, avanzando hacia una mayor igualdad" (p. 16).

Aun cuando habría que reconocer las excelentes intenciones del documento, si los autores hubieran prestado más atención a la realidad concreta que pretendían estudiar, y al acumulado de conocimientos sobre el tema, hubieran descubierto que los procesos de fronterización en el caso concreto (aunque no exclusivamente) de América Latina no han estado caracterizados por arreglos negociados equitativos, sino por relaciones desiguales, por niveles muy altos de informalización, por regímenes políticos fronterizos militarizados, infrademocráticos y signados por la corrupción. También hubieran conocido que existen en nuestro continente notables discrepancias entre estados, sociedades e identidades, y que los primeros no son entidades con funcionamientos institucionalizados y acotados por el escrutinio público que obligan a la gestión transparente del "bien común". No menos importante, se hubieran visto obligados a admitir que los proyectos de integración supranacional en ocasiones han inducido - por acción o por omisión- procesos de fronterización más excluyentes y discriminatorios, como Jaquet (2008) y Giménez (2010) han argumentado respecto al

\footnotetext{
${ }^{3}$ Entendemos por comunidad epistémica, siguiendo a Haas (1992), una red de profesionales legitimados por sus niveles comprobados de competencia en un campo, desde donde pueden incidir de manera sustancial tanto en la producción de un discurso académico como de políticas públicas.
} 
Mercosur. Para concluir que los procesos de fronterización en América Latina —sus correlatos económicos, las articulaciones sociales y sus raíces histórico/culturales, entre otras aristas vitales para el entendimiento de estos ensamblajes espacio/temporales transfronterizos— son, de manera descarnada, “(...) sistemas relacionales sustentados en el conflicto" (Grimson, 2000, p. 18).

En esta presentación argumental nos proponemos contribuir al debate sobre el tema de las concertaciones transfronterizas en nuestro continente, entendidas como todo proceso de negociación regular que ocurre entre actores transfronterizos y cuyo valor agencial reside en la adopción de acuerdos para gestionar procesos regulares de intercambios que modelan estos territorios y, la naturaleza de los procesos de fronterización que tienen lugar. En primer lugar, el artículo discute conceptualmente los procesos de fronterización en el capitalismo neoliberal, y, en segundo lugar, de qué manera estos procesos han incubado modalidades de concertaciones fronterizas en las dos regiones que más han influido en el pensamiento académico latinoamericano: en la Unión Europea y en la frontera México-Estados Unidos. Finalmente avanzamos algunas ideas sobre América Latina, sus fronteras y las experiencias reales de concertación transfronteriza, donde proponemos de manera preliminar y con fines absolutamente operativos, una tipología de experiencias de concertación a partir de sus orígenes.

El artículo está animado por una metodología deductiva, apoyada en el análisis de la producción académica existente y de la información empírica que tienen los autores desde sus trabajos en varias situaciones fronterizas continentales. No obstante, como los lectores notarán, las ideas aquí expuestas son presentadas de una manera ensayística y tienen un tono polémico. Ello persigue un objetivo vital para el ejercicio intelectual: motivar la discusión como procedimiento epistemológico, inseparable de lo que Morín (2000) llamaba "el derecho a la reflexión en contraposición a la confrontación ciega de los hechos o la verificación testaruda de hipótesis fútiles" (p. 59).

\section{Los procesos de fronterización en el capitalismo neoliberal}

Una manera de percibir la historia del capitalismo es como un proceso complejo de contrapunteo y complementación entre, lo que Tilly (1990) denominó, las lógicas del capital y de la coerción. En cada uno de estos momentos se han generado rearticulaciones territoriales que han redefinido las fronteras interestatales, tanto respecto a sus despliegues espacio/temporales como a sus usos sistémicos. Son los llamados procesos de fronterización que aquí consideramos (de acuerdo con Van Houtum \& Van Naerssen, 2005, p. 127) como aquellos procesos continuos de reestructuración del poder territorial que ocurren en ámbitos de fronteras internacionales y que determinan las dinámicas que personas, capitales, bienes, informaciones y discursos sostienen en relación con ellas.

Históricamente, los territorios fronterizos han constituido "territorialidades superpuestas" (Agnew \& Oslander, 2010) afectadas por la confluencia de soberanías políticas y tejidos culturales diferentes, siempre contradictorios y en ocasiones contendientes. Pero durante la fase del capitalismo mercado internista, dominante en el siglo $\mathrm{xx}$ —según Hobsbawn (2015) con "un proteccionismo tan defensivo que rozaba la autarquía" (p. 142) — y del apogeo regulador de los estados nacionales, las 
fronteras resultaban lugares liminares, "confines de la patria" obligados a mirar hacia "los núcleos vitales" de las naciones. Sus dispositivos institucionales estaban dirigidos a administrar el contacto y la separación respecto a los otros, y podían definirse claramente desde su naturaleza instrumental (afirmaba Raffestin, véase compilación de Cerrarols et al., 2018) expresada en cinco funciones proteccionistas: legal, fiscal, de control, militar e ideológica. Las fronteras eran un tema de la geopolítica clásica y, por consiguiente, la fronterización daba cuenta, ante todo, de una habilitación de los límites que Prescott (2015) explicó como una secuencia de acciones —locación, delimitación, demarcación y administración- acorde con “(...) las funciones estatales aplicadas a los límites” (p. 63). La noción de lo transfronterizo era entonces liminar y remanente.

El advenimiento del capitalismo neoliberal - cuyo rasgo decisivo para nuestros fines es la adquisición por el capital de recursos de movilidad sin precedentes y muy superiores a las capacidades de contención, tanto de los estados nacionales como de las comunidades- acarreó la conversión de las fronteras en recursos económicos (Sohn, 2014) basados en la explotación de las ganancias diferenciales y la consiguiente localización del intercambio desigual. Para Soja (2005, p. 33) ello implicó una particular complejidad de las "coreografías ontológicas" de los procesos de fronterización, repleta de "paradojas binarias" ${ }^{4}$ construidas desde una refuncionalización que no renuncia a viejos usos de control, sino que les incorpora y resignifica. Lo que convirtió, para poner un ejemplo, viejos dilemas centrales, como la contraposición entre contacto y separación, en un resultado fenoménico que, aun conservando su significado político, resulta de menor valor heurístico.

Las fronteras internacionales aún separan y contactan según las conveniencias, pero, sobre todo, clasifican a los sujetos y los disciplinan en función de los procesos económicos y políticos que configuran lo transfronterizo. ${ }^{5}$ Los trabajadores devienen en aliens sin derechos, más redituables en cuanto ofertantes de fuerza de trabajo, y sin el costo adicional de la reproducción de la vida familiar que dejan atrás (Kearney, 2008). Las mercancías/bienes consuetudinarios, que han constituido recursos vitales de sobrevivencia de las comunidades se convierten en contrabando. Las culturas de los otros, en productos inocuos previamente folclorizados. Y los mismos otros, a fuerza de contactos, se convierten en una suerte de otros aquiescentes, íntimos, beneficiados por cuotas de tolerancia constitutiva de un orden cosmopolita con el que el neoliberalismo convive.

Estas consideraciones generales no omiten la existencia de tipos diferentes de procesos de fronterización a partir de las realidades empíricas, y que resultan de vital

${ }^{4}$ Escribe Soja:

Observe las paradojas binarias y los opuestos atraídos que componen el proceso limítrofe: circunscribir/conectar, aislar/abarcar, separar encontrarse, confinar acercarse, limitar/tocar. Las fronteras por definición llevan a crear y tomar partido, a producir y ocupar espacios opuestos, y a muchas dicotomías asociadas: adentro/afuera, inclusión exclusión, nosotros/ellos. Pero también invitan simultáneamente a la transgresión, un movimiento más allá de los límites y recintos definidos de nuestra vida para abrir nuevos lugares y espacios, buscar alternativas conciliadoras, síntesis creativas, resolver hibridaciones (2005, p. 33).

${ }^{5}$ Según Mezzadra y Neilson (2013), las fronteras devienen "métodos" del capitalismo neoliberal para la multiplicación e intensificación de los procesos de trabajo en contextos de mayor heterogeneidad de la fuerza de trabajo. Y en consecuencia no son solamente lugares de flujos, sino articuladores y organizadores de estos: "Claramente, afirman, el capital busca relaciones de fronteras como un medio de organizar y reforzar sus operaciones" (p. 7). 
importancia para el análisis de las concertaciones. En última instancia, un territorio es un producto multidimensional. Y su multidimensionalidad remite a factores como el escenario histórico, cultural y ambiental en que tiene lugar; a la "coherencia estructurada" de su economía política (Harvey, 2014) que se construye tanto desde prácticas sociales de sobrevivencia como, desde estrategias de acumulación; y, finalmente, a la naturaleza de su régimen político, el balance de sus prácticas topocráticas y adhocráticas (Leresche \& Saez, 2002) y sus contextos geopolíticos.

Christopher Sohn (2014) ha ofrecido un ejercicio taxonómico basado en la configuración de dos tipos ideales de lo que llama "integración transfronteriza", y desde ellos, de diversos cruces situacionales. En primera instancia, Sohn describe lo que denomina un "modelo geoeconómico", que correspondería al tipo de relacionamiento que da vida a la inmensa mayoría de las regiones transfronterizas contemporáneas. Su principal razón de funcionamiento es el aprovechamiento de las ganancias diferenciales y por tanto convive con grandes disparidades territoriales que se engrandecen con el funcionamiento del modelo. Implica la perpetuación de la frontera como una fuente de ganancias, de manera que "(...) este tipo de régimen transfronterizo va de la mano con una fuerte división del espacio social y funcional, que condiciona cualquier voluntad política en favor de la convergencia territorial" (Sohn, 2014, p. 597). Aunque puede contener cooperación que disminuye incertidumbres y aumenta réditos, esta regularmente es opcional y marginal a los procesos decisivos de funcionamiento del modelo. En el otro extremo existiría un segundo modelo llamado "territorial" que contiene un proceso de integración basada en una lógica de "hibridación transcultural y de movilización de la frontera como un objeto de reconocimiento territorial y simbólico" (p. 598) donde la intención es ir más allá de una simple operación de mercadeo territorial para dar lugar a una forma de integración que trasciende y difumina al límite. La cooperación es aquí un elemento fundamental de cohesión, y eventualmente puede producir regímenes políticos total o parcialmente fusionados.

Se trata, decíamos, de dos tipos ideales que Sohn conjugaba en gradaciones y combinaciones que omitimos en esta consideración. Lo que nos interesa resaltar es que el modelo territorial — claramente ubicado en una perspectiva posnacionalista que genera una fronterización que apunta a la negación de la frontera- solo ha estado presente en el proceso de integración europea, y en consecuencia solo ha afectado las fronteras internas de ese espacio. Y ha sido así en la misma medida en que la Unión Europea ha estado dotada de una ambición posnacionalista (dentro de los confines europeos), de reconstrucción de las comunidades fronterizas desde una adecuación legal sustantiva - cuyo punto de partida fue la Carta Europea de 1981- y una notable locación de recursos billonarios desde los conocidos programas Interreg. En cambio, el modelo geoeconómico ha sido la regla de funcionamiento de las fronteras internacionales activas y ha tenido su despliegue típico en la frontera de Estados Unidos con México. Una y otra experiencia se han constituido - debido a las densidades de estudios y a la fuerza de las entidades involucradas en ellos- en dos casos paradigmáticos a los que no ha podido sustraerse la academia latinoamericana. Por ello, imposibilitados, por razones de espacio, de discutir de forma exhaustiva lo que se ha producido teóricamente sobre el tema —una bibliografía rica, numerosa y creciente- se examinan algunos estudios que han tratado de explicar la naturaleza y los alcances de los procesos de concertación en cada contexto, y que, aún en las proyecciones más optimistas, indican falencias considerables. 


\section{Las dos referencias experienciales: las eurorregiones y la frontera México/Estados Unidos}

Los dispositivos territoriales y de concertación transfronterizos por excelencia de la Unión Europea han sido las eurorregiones —unidades con identidades formales, institucionalidades y recursos propios y diferentes de los estados nacionales que les comparten-, de las que Markus Perkmann (2002) dio tempranamente cuenta en un minucioso estudio que sigue siendo un punto de referencia. Al partir del hecho de que estas regiones transfronterizas fueron construidas desde negociaciones de actores formales, principalmente estatales, los argumentos de Perkmann se remitieron a la acción de la cooperación transfronteriza formal. De acuerdo con el autor, la cooperación transfronteriza formal antecede a los programas de la Unión Europea, y sus pistas se hallan en varios "emprendimientos institucionales" que tuvieron lugar en los años de 1950. La Unión Europea, desde la década de 1990, agregó a esta tendencia una cobertura multinivel — política y técnica- más coherente y cuantiosos fondos de incentivos, lo que no solo incrementó exponencialmente el número de "emprendimientos" sino que hizo más complejas y ambiciosas sus agendas. Pero, aun así, una parte considerable de los proyectos de cooperación no pasaban de ser “(...) entidades tecnocráticas, a través de las cuales las autoridades locales viabilizan sus propios proyectos" (Perkmann, 2002, p. 121). En todos los casos, recalcaba, “(...) los actores participantes están fuertemente orientados hacia sus propios intereses territoriales y organizacionales" (p. 109), lo que generaba usos unilaterales de los fondos asignados. Aunque en un estudio posterior (Oliveras et al., 2010, p. 38) se otorgaba a las eurorregiones un salvoconducto histórico como "(...) un nuevo modelo institucional (...) que redefine al modelo westfaliano”, que llamaba a la prudencia en los vaticinios optimistas.

Sohn (2018) ha calculado la existencia de 130 estructuras de concertación transfronteriza sobre el mapa europeo, 80 de las cuales son eurorregiones, organizadas formalmente como entidades autónomas públicas o privadas con aparatos administrativos y técnicos propios y, eventualmente, órganos representativos. En particular, centra su atención en la emergencia de "metrópolis transfronterizas", un término controversial adoptado del urbanismo fronterizo norteamericano que curiosamente pudiera tener aquí mayores visos de aplicabilidad que en su lugar de origen. De hecho, afirma Sohn (2018) que "estas regiones transfronterizas han logrado desarrollar algunas de las formas más avanzadas de cooperación en los campos de planificación urbana, transporte y desarrollo económico y algunas incluso lograron desarrollar infraestructuras transfronterizas" (p. 304), y con ello colocarse ventajosamente en los circuitos inversionistas. No obstante, coincidía en el pesimismo acerca de la inexistencia de identidades compartidas y en cambio la proliferación de resentimientos entre las partes coaligadas.

Si estos obstáculos han estado presentes en Europa, buena parte de cuyas fronteras no encierran grandes desigualdades socioeconómicas, y donde las políticas de integración han apuntado a considerarlas como cicatrices atávicas de la historia, es plausible considerar que en el espacio fronterizo mexicano-estadounidense, donde han primado los usos "geoeconómicos" de las fronteras, los procesos de concertaciones transfronterizas han tenido un derrotero menos sonriente. 
Aunque el llamado Tratado de Libre Comercio de América del Norte (TLCAN/ NAFTA) es un acuerdo de fuerte connotación política, concertado entre estados y que implica cesiones parciales de soberanía por ellos, no aspira a una comunidad política. Su motor es el mercado y, su leit motif mayores ganancias a partir de una economía política que aprovecha e intensifica la desigualdad. Y, aunque ha incorporado programas de control de externalidades negativas —sea por presiones sociales o por la adopción de códigos de responsabilidad social— estos son marginales y termina primando la desigualdad expresada en la hegemonía geopolítica y económica de uno de sus miembros: Estados Unidos.

Los estudios sobre el tema revelan una gran cantidad de proyectos y organizaciones de concertación, los que han sido descritos por autores como Scott (2002) y, más recientemente, Barajas (2015) quien contabilizaba 83 "actores institucionales" con agendas y niveles diversos que incidían en el tema. Algunos de estos proyectos son funcionalmente muy relevantes y abarcan la totalidad de la frontera, como el International Boundary Watter Commission de 1944 o el más reciente pero obviamente muy significativo North American Development Bank. Otros son proyectos más discretos en sus radios de acción, recursos y capacidades de incidir en las tomas de decisiones públicas. Según Mendoza y Dupeyron (2020, p. 73) estos proyectos estaban principalmente destinados a “(...) promover los negocios en los dos lados del límite, y están estructurados como un campo de acciones estratégicas enfocados hacia la actividad económica", mientras que aquellas otras propuestas que apuntaban a crear ámbitos de cooperación en temas culturales, ambientales y educacionales eran impulsadas por actores emergentes con menos recursos y experiencias.

Scott (2002) advirtió tempranamente que estos proyectos tenían cierto valor en cuanto a romper barreras sicológicas y fomentar una cultura de riesgos comunes, pero destacaba - con referencia al espacio Arizona-Sonora- que "los resultados reales alcanzados por estas iniciativas transfronterizas pudieran parecer magros” (p. 201). Una década después, Tony Payan (2010) reiteraba los mismos argumentos y perfilaba una crítica en dos sentidos. En primer lugar, resaltaba que la abrumadora mayoría de ellos no rebasaban un nivel de "cooperación" en que se identificaban objetivos y temas comunes, lo que mantenía a cada parte la individualidad institucional, ${ }^{6}$ para condenar las interacciones transfronterizas a un "(...) ejercicio espontáneo con resultados estrechos y objetivos temporales" (p. 234). En segundo lugar, la ausencia de una gobernanza transfronteriza apoyada en "(...) un sistema de incentivos institucionales, que crea, formaliza y legitima mecanismos (...) para desarrollar capacidades concretas de colaboración" (p. 241).

En un vigoroso estudio, Josiah Heyman (2010) ha situado la discusión sobre los territorios transfronterizos en la frontera México/Estados Unidos en la coexistencia de dos "fuentes de hegemonía". Una se deriva del poder de los estados nacionales que involucra fuerzas de control y simbologías. La segunda proviene de los requerimientos de la globalización capitalista que implica mayor fluidez en los tránsitos de factores

\footnotetext{
${ }^{6}$ Payan (2010) explica en su obra una interesante taxonomía de proyectos transfronterizos. El nivel más precario correspondía a la coordinación, que ocurría cuando las partes persiguen objetivos diferentes y se articulan para evitar mutuas interferencias y por tiempos limitados. En el extremo superior mencionaba la colaboración, cuando existe compartición de objetivos e intereses, con instituciones permanentes y confianza mutua, lo que favorece la regulación de los procesos de manera sostenida, efectiva y equitativa. Justo en el centro se producía la cooperación antes mencionada, y que constituía el nivel superior a que usualmente podían acceder los acuerdos transfronterizos.
} 
económicos. Ambas son, afirmaba Heyman, "estructuras rivales" pero se trata de una rivalidad tácita, relativa, pues finalmente ambas hegemonías apuntan al reforzamiento del status quo: “(...) refuerzan lo aceptado, lo normal, lo inalterable” (2010, p. 31). Y ambas asumen alineamientos culturales diferentes que el autor remite principalmente a los posicionamientos clasistas de los sujetos en cada estructura.

La propuesta de Heyman contiene un valor analítico apreciable en los estudios de la frontera estadounidense con México, donde, como ya se dijo, han sido frecuentes los estudios que han querido mostrar escenarios de hibridaciones, convergencias y fusiones de dos realidades complejas (Herzog, 1990; Martínez, 1994; Alvarez, 1995; Anzaldúa, 1999; Dear \& Leclerc, 2003), explícita o implícitamente criticados por Vila (2003), Alegría (2008) y Grimson (2000), entre otros. Sin embargo, su visión insiste en una noción fragmentada de los territorios transfronterizos — la política nacionalista y la economía globalizadora como "estructuras rivales" - que dificulta entender la realidad sistémica subyacente.

Pero, sobre todo, para el fin que aquí se ocupa, abre una puerta a la ilusión de que desde la segunda "fuente de hegemonía" se genera un escenario más propicio de integración por la generación de un cosmopolitismo de fuerte sello clasista que constituye “(...) el marco cultural apropiado para la conducción de la globalización” (Heyman, 2010, p. 30). Por consiguiente, si se adoptaran adecuaciones institucionales en pos de una mayor "armonía estructural" entre los estados de ambas partes —como también han sugerido Payan (2010) y Ganster y Collin (2017) - pudiera suponerse la creación de verdaderos procesos de integración mediante políticas superiores de colaboración.

No se quiere decir que lo planteado por los autores antes mencionado sea innecesario, solo que resulta adjetivo frente a una tensión mayor que ocurre al mismo interior de los procesos de producción y reproducción económica de estos territorios y que son inherentes a estas modalidades de fronterización geoeconómicas (Sohn, 2014). No se trata simplemente de que la interacción económica transfronteriza se apoye en y coexista con la explotación de las desigualdades, sino de que al hacerlo genera una economía política basada en un intercambio desigual que profundiza la inequidad, tal y como han demostrado - para la misma frontera Mexico/Estados Unidos- Gerber y Anderson (2015) y desde el punto de vista espacial Fuentes y Peña (2010). Y de lo que la política da cuenta mediante estructuras que solo estarían en condiciones de negociar aspectos secundarios de la relación transfronteriza.

\section{Las fronteras latinoamericanas: informalidad, centralismo y autoritarismo}

Muy pocas regiones transfronterizas latinoamericanas se han constituido desde estrategias de acumulación de gran escala, como es el caso de la frontera México/ Estados Unidos. Se pueden encontrar regiones cuyas economías políticas engarzan de manera fundamental con la economía global —el caso, por ejemplo, de la región trasfronteriza ubicada en el departamento de Alto Paraná en Paraguay y los estados de Matto Grosso do Sur y Paraná en Brasil (Massi \& Falabella, 2005)—o que se organizan en torno a flujos comerciales internacionales como ocurre en la región Corumbá/Puerto Quijarro en la frontera de Brasil y Bolivia (Batista da Silva, 2013) o los departamentos de Santander Norte (Colombia) y Táchira (Venezuela) antes de la crisis en este último 
país (Valero, 2008). Pero la mayoría de estas regiones son lo que Dilla y colaboradores (2020) denominan "regiones autocontenidas", cuyos intercambios económicos —aun cuando mantienen vínculos con otras escalas- se resuelven fundamentalmente en el mismo plano local. En todas las escalas, las relaciones informales tienen un rol fundamental en la sobrevivencia de las economías familiares y de una miríada de actores concertados según "usos y costumbres", que operan en áreas grises y cuyas miradas no rebasan el mero plano existencial. ${ }^{7}$

Ninguna es resultado de una concertación política posnacionalista a la usanza europea. Los estados latinoamericanos siguen siendo medularmente westfalianos, a lo que se ha sumado la fuerte presencia militar y paramilitar en las fronteras latinoamericanas. Estas han sufrido históricamente de niveles muy altos de determinación por instituciones armadas, con variaciones en cuanto a sus niveles de especialización, lo que deja menos espacio que en otras latitudes a las autoridades civiles. Esta presencia se ha visto reforzada por el incremento - real o construido con fines políticos- de las denominadas "nuevas amenazas", tales como tráficos ilícitos de drogas, armas, personas (con el incremento de los flujos migrantes intracontinentales), acechanzas terroristas o trasmisiones de epidemias, elemento este último llevado a su máxima expresión por la pandemia COVID-19 que convirtió nuestras fronteras en escenarios de ejercicio de la biopolítica más cruda, tal y como han señalado Ovando y colaboradores (2020) en referencia al espacio surandino. Estos procesos de securitización agregan a la modalidad geoeconómica de la fronterización latinoamericana nuevos ingredientes de control y disciplinamiento de los otros, y también mayores obstáculos para la cooperación transfronteriza. Aunque el continente ha conocido diferentes proyectos integracionistas que han oscilado desde el proteccionismo desarrollista hasta el "nuevo regionalismo" neoliberal tal y como lo ha discutido Molano (2007), ninguno de ellos se ha propuesto una superación posnacionalista de las fronteras internacionales, y raras veces han tenido proyecciones específicas hacia las fronteras como territorios.

En tal contexto, es entendible que en nuestro continente las experiencias de concertaciones transfronterizas hayan resultado limitadas tanto en sus aspiraciones como en sus logros. Como se anotó, aunque se han producido estudios de alta calidad, no existe un inventario medianamente exhaustivo de estas experiencias, cuestión que debe ser resuelta por investigaciones futuras. Pero de manera hipotética y preliminar, pudiéramos agrupar estas experiencias en tres tipos, atendiendo a sus orígenes organizativos y escalas: $(i)$ las provenientes de iniciativas locales; (ii) las originadas en el seno de los proyectos de integración existentes y, (iii) las provenientes de esquemas binacionales de gobernabilidad de fronteras.

\footnotetext{
${ }^{7}$ Por razones de espacio, se abstiene de una discusión sobre la relación entre informalidad, ilegalidad y actividades criminales. Valga solo mencionar, de acuerdo con Dorfman (2020), que

(...) las ganancias de esas operaciones comerciales no se acumulan en los lugares fronterizos; es poco lo que se queda en los nodos marginales de estas redes. La plusvalía generada por el contrabando tiene también su geografía: en las fronteras poco se acumula, pues el "trabajo nocturno" es un eslabón débil en la cadena que realiza su ganancia en los centros consumidores. (p. 159)
} 


\section{Experiencias de concertaciones transfronterizas provenientes de desarrollos locales}

Muchas de las coexistencias comunitarias transfronterizas en América Latina son conglomerados sociales que anteceden a las propias fronteras, o a los momentos en que los estados nacionales decidieron demarcarlas y habilitarlas como puntos controlados. En ocasiones las fronteras separan pueblos originarios, y las socializaciones nacionalistas solo han conseguido modificar parcialmente las autopercepciones identitarias. En otros casos, las fronteras son continuamente retadas por relaciones consuetudinarias, sean familiares, amistosas o de lealtades localistas. En términos espaciales, se trata de poblaciones tan cercanas que en ocasiones los límites se difuminan en cientos de cruces cotidianos, como son los casos de Chui y Chuy en el borde brasilero/uruguayo (Domínguez, 2010); de Tabatinga y Leticia en el límite amazónico de Colombia y Brasil (Nogueira, 2008); o de los dos poblados llamados Desaguadero en el borde boliviano/peruano (Sánchez, 2019).

Por ello, es usual que las autoridades estatales y los dirigentes sociales establezcan contactos para buscar soluciones a problemas puntuales que entorpecen la marcha de las relaciones mutuamente ventajosas. Lo hacen en torno a horarios de cruces, fiestas patronales y otros temas cotidianos, y constituirían lo que Blatter (2003) denomina "conexiones" entendidas como acciones informales, poco estructuradas y no jerárquicas. ${ }^{8}$ Este tipo de interacción es perdurable, pero está constreñida a temas muy parroquiales. Sin embargo, puede ocurrir que estas conexiones sean influidas por agentes externos —cooperación internacional, gobiernos nacionales, grupos técnicos- que inducen su transformación en concertaciones más estructuradas. Ejemplos de ellos han sido el "Comité Intermunicipal Transfronterizo" (CIT) en la frontera haitiano/dominicana y la "Alianza Estratégica Aimaras sin Fronteras" (AEAF) en la triple frontera de Perú, Chile y Bolivia.

El primer caso tuvo lugar entre 2006 y 2012 en la franja fronteriza donde colindan la provincia dominicana de Elías Piña y el departamento central haitiano. Este fragmento de la franja fronteriza dominico/haitiana se ha caracterizado históricamente tanto por sus notables niveles de pobreza como por la porosidad y la proliferación de vínculos micro-comerciales, culturales y religiosos. En la primera década del siglo xxi coincidieron en la parte dominicana una serie de agencias y grupos de cooperación que proveyeron fondos y recursos humanos, lo que instaló entre algunos alcaldes dominicanos la idea de que una acción mancomunada que incluyera a la parte haitiana podría provocar una afluencia mayor de recursos para impulsar varias obras de desarrollo. Este impulso externo -al que se sumó el acompañamiento de una asociación técnica denominada Ciudades y Fronterasconllevó a la formación del cit con reuniones semestrales de los alcaldes, una oficina técnica que proveyó asesoramientos para instrumentar microproyectos de desarrollo y

\footnotetext{
${ }^{8}$ En su artículo citado, Blatter (2003) establece cuatro tipos ideales de instituciones de concertación transfronteriza: comisiones, cuando se trata de instituciones creadas por acuerdos internacionales para resolver temas específicos que afectan la interdependencia; conexiones, entendidas como instituciones dirigidas a soluciones específicas y que son informales, poco estructuradas y no jerárquicas; coaliciones si se apoyan en afinidades idealistas, regularmente politizadas con aspiraciones solidarias; $y$, finalmente, las consociativas que combinan idealismo con fuerte formalización, tienen fuertes contenidos políticos y portan agendas amplias.
} 
algunas inversiones puntuales para el mejoramiento de servicios económicos y sociales desde las municipalidades. Fue también una oportunidad de reconocimiento mutuo y de ofertas culturales que pudieron disfrutar las comunidades de ambos lugares. En su momento climático, contaba con la membresía de seis municipios dominicanos y ocho haitianos, limítrofes o muy cerca del límite.

El proyecto, sin embargo, mostró rasgos tempranos de agotamiento. En primer lugar, nunca hubo una estrategia multinivel, sino que pervivió con la apatía y eventualmente la hostilidad de las autoridades nacionales, celosas de una frontera que consideraban un tema de administración central. Los gobiernos locales, con muy pocos recursos económicos y humanos, fueron incapaces de producir una sinergia autosostenida, y cuando cesó el apoyo externo y cambiaron los alcaldes fundadores, el cit declinó abruptamente y, aunque continuó existiendo (y de hecho fue replicado en otros puntos de la frontera dominico/haitiana) en realidad se redujo a un espacio retórico sin incidencias prácticas.

Aun cuando sus logros - materiales y simbólicos- son indudables, habría que destacar que su quehacer fue exitoso mientras anduvo por un área blanda de la relación transfronteriza -intervenciones puntuales, intercambios culturales- pero se detuvo cuando se trataba de analizar a los elementos claves de esa relación basada en el intercambio desigual y el trato discriminatorio dado a los haitianos en las ferias comerciales, siempre ubicadas en territorio dominicano. En términos operativos, el CIT reprodujo esa relación desigual en una suerte de dependencia de la parte haitiana hacia la parte dominicana (Dilla, 2016) que tenían a su favor mayores recursos materiales y humanos.

Más compleja, y conocida, ha sido la Alianza Estratégica Aimaras sin Fronteras (AEAF) que tuvo lugar entre 2001 y 2015 en la región centro/sur andina, donde confluyen las jurisdicciones chilena, boliviana y peruana, y cuyo signo distintivo es una factura cultural aimara. Estas características culturales, y su ubicación en un territorio muy agreste geopolíticamente, atrajeron la atención de actores muy diversos - la Cespi italiana, la cooperación belga, el Banco Mundial, el Banco Interamericano de Desarrollo (вІD) у algunas instancias del estado chileno- que le acompañaron con recursos técnicos y económicos vitales para su despegue. Hacia 2012 se reportaban unos 57 municipios involucrados, la mayor parte bolivianos, un hecho inédito en la región en que, al decir de Rouvière (2014, p. 38) los alcaldes “(...) emprenden políticamente la frontera armando redes a escalas múltiples, tanto con los bancos internacionales como con los centros políticos y sus homólogos fronterizos".

Sin embargo, a pesar de sus brillos mediáticos y de la atención que recibieron del mundo intelectual que González (2019) remitió al influjo del espejo foucaltiano, este proyecto navegó siempre en medio de fuertes tensiones que lastraron su desenvolvimiento.

Por un lado, la AEAF resultaba una entidad con aspiraciones posnacionales sobre bases identitarias ancestrales en un contexto geopolítico que nunca asumió esta posibilidad. Esto implicaba frecuentes encontronazos entre las autoridades municipales involucradas y sus respectivas contrapartes regionales y nacionales en condiciones de indefensión legal (Rouvière, 2008), sin que existiera —más allá de algunas intervenciones adjetivas - una estrategia multinivel. Según estos encontronazos se producían en detrimento del acceso a recursos y de la posibilidad previsible de éxitos en el desarrollo local, generaban un clima de solidaridades. Pero cuando los conflictos entre las naciones involucradas, y en particular entre Chile y Bolivia, subieron sus decibeles, erosionaron los procesos de concertación. A partir de 2012 el proyecto 
comenzó a extinguirse hasta quedar limitado a una alianza esencialmente boliviana y sin pretensiones transfronterizas (Aranda \& Salinas, 2017).

Una segunda fuente de tensiones, probablemente la más importante, radicaba en la distancia entre las metas proclamadas por los dirigentes de la AEAF y las necesidades sentidas de las comunidades. La alianza se dotó de un programa de acción de mediano plazo, cuyo principal argumento era la elevación del nivel de vida de la población aimara en un contexto de extrema pobreza, ausencia de políticas sociales y carencias infraestructurales básicas. Para conseguir resultados en este sentido, los alcaldes previeron un plan estratégico dirigido a posicionar la región en la economía global a partir principalmente de la oferta de servicios culturales y turísticos apoyados en su recurso identitario. Sin embargo, la agenda de la AEAF no se basó en un dictamen participativo y de hecho se convirtió en una concertación cupular, de manera que la etnización de lo político, agudamente discutida por Rouvière (2014), fue realmente un intento de las élites locales para conseguir un control más efectivo de dos recursos: la frontera y la identidad ancestral. La acción de los alcaldes rurales andinos tendió a perpetuar relaciones de poder vertical en desmedro de los pobladores de las comunidades. ${ }^{9}$

\section{Experiencias de concertaciones transfronterizas originadas en el seno de los proyectos de integración existentes}

Otra fuente de experiencias de concertación transfronteriza proviene de los proyectos integracionistas supranacionales que, como decíamos, han avanzado muy poco en el tema que nos concierne. Un ejemplo de ello es el Mercosur, sin lugar a duda el proyecto latinoamericano de mayor relevancia espacial, demográfica y económica. En comparación con otros proyectos integracionistas latinoamericanos, el Mercosur produjo una incorporación tardía del tema fronterizo. Y cuando lo ha hecho, se ha tratado de proyectos limitados en alcance y expuestos al fallecimiento por falta de voluntad política. Un ejemplo de ello ha sido el llamado Grupo Ad Hoc de Integración Fronteriza (2002) que funcionó algunos años en medio de la apatía de los estados miembros hasta su extinción (Oddone \& Matiuzzi, 2017). Recientemente (diciembre de 2019) se promulgó otra disposición —el Acuerdo sobre Localidades Fronterizas Vinculadas- que homogeneiza los contactos lícitos en toda la geografía del territorio

${ }^{9}$ Ejemplo de esto fue lo señalado por el periódico El Morrocotudo:

El 16 de mayo de 2008, en el tripartito frontera Perú-Chile-Bolivia, los alcaldes de Charaña, Palca y General Lagos de Bolivia, Perú y Chile, respectivamente, realizaron una Feria de Camélidos Sud Americanos, que causó el descontento de las comunidades aymaras del lugar. Cada uno de los alcaldes dispuso de cada una de sus arcas municipales, más de cien mil dólares para un festejo donde las comunidades no han ganado nada. (Citado por González, 2019, p. 121)

Y en el mismo texto González citaba el discurso de un líder comunitario:

\footnotetext{
Estamos desprotegidos, no estamos contentos con sus alcaldías, nosotros queremos que nuestros Jilakatas vuelvan a tomar autoridad en nuestros territorios, porque queremos cuidar nuestra madre tierra, no queremos que se siga saqueando nuestras aguas superficiales y subterráneas, porque son sagradas para nosotros y porque queremos legar a nuestras futuras generaciones un porvenir de paz y alegría verdadera para todos. (González, 2019, p. 122)
} 
del Mercosur, pero remitida a zonas urbanas y con un repertorio discreto y conservador de nuevos derechos (trabajo y usos de servicios sociales) sin reconocimiento explícito de la dimensión transnacional como sujeto de derecho. El acuerdo contempla impulsar los procesos de conurbación mediante obras infraestructurales en unas tres decenas de aglomeraciones urbanas. Huelga anotar que lo reciente de este acuerdo y la ocurrencia de la epidemia del COVID-19 impiden un balance de sus efectos reales.

Paikin (2012), en un agudo ensayo, veía estos espacios como condensaciones contradictorias de

(...) las lógicas de competitividad económica, propias de los actores privados, las tensiones en relación a las competencias inter e intra estatales, las similares pero diferentes culturas empresariales y organizacionales, los resquemores nacionalistas y los problemas concretos en términos de infraestructura y logísticas (...). (p. 107)

Y coincidía con Giménez (2010) y Jaquet (2008) — ya citados— en que

(...) la llegada del Mercosur y las nuevas relaciones bilaterales generaron mayores complicaciones para el tránsito fronterizo que las que existían con anterioridad, provocando un sentimiento de desilusión y rechazo a la integración que antes de acercarlos a sus vecinos, los alejaba. (Paikin, 2012, p. 112)

para concluir que “(...) no habrá posibilidad de desarrollo conjunto sin la profundización de la ciudadanía regional” (Paikin, 2012, p. 112). Por ello no es casual que el Mercosur no haya tenido efecto significativo en las legislaciones nacionales sobre fronteras de sus estados miembros.

Más interesante para nuestros fines ha sido la Comunidad Andina de Naciones (CAN). En 1999, la CAN dio un paso adelante con la promulgación de un primer manojo de lineamientos agrupados en el documento "Política Comunitaria de Integración y Desarrollo Fronterizo" y la constitución de un grupo de alto nivel. Al mismo tiempo, sus estados miembros fueron motivados a introducir legislaciones que sustanciaban las constituciones respectivas, introducían institucionalidades específicas de desarrollo fronterizo, reconocían los espacios transfronterizos como sujetos de derecho y les proveían de mecanismos de coordinación formalmente reconocidos, tal y como han discutido Dilla y Hansen (2019) para la experiencia colombiana.

La pieza clave de esta institucionalidad fue la creación desde 2001 de las Zonas de Integración Fronteriza (ZIF). Las ZIF fueron la respuesta institucional a una tipología espacial que caracterizaba a las regiones fronterizas, según Sánchez (2015) como zonas aisladas y periféricas “(...) respecto a los centros dinámicos” (p. 88) y en consecuencia se entendía su evolución ligada a reforzar su relación con el territorio nacional respectivo. Su razón, según el documento constitutivo (CAN, 2001) era la adopción de políticas y proyectos “(...) para impulsar el desarrollo sostenible y la integración fronteriza de manera conjunta, compartida, coordinada y orientada a obtener beneficios mutuos, en correspondencia con las características de cada uno de ellos" (p. 16). Y desde aquí las ZIF fueron diseñadas como engranajes burocráticos, sin atención a las condiciones culturales y a las potencialidades de los espacios fronterizos.

En un exhaustivo estudio sobre las fronteras amazónicas de Colombia, Zárate y colaboradores (2017) afirmaban que las ZIF adolecían de diseños territoriales disfuncionales e insuficiencias fundamentales en la legislación y la reglamentación complementarias, por lo que “(...) los instrumentos bilaterales de integración (...) no 
solo han sido inadecuados e insuficientes sino también excluyentes y, lo que es peor, no consultan la realidad fronteriza de nuestros países" (p. 161). Nilo Meza (2011) ofrece un ejemplo elocuente: zIF Perú-Bolivia contiene 905226 kilómetros cuadrados, más grande que Paraguay y Uruguay juntas, que abarcan $70 \%$ del territorio peruano y $82 \%$ del boliviano. En tal contexto, dice Meza, "cualquier propuesta de planificación naufragaría solo comenzando el diseño" (2011, p. 102).

Sin lugar a duda, la ziF emblemática fue la que se conformaba en torno al complejo urbano transfronterizo de Cúcuta en Colombia y San Antonio/Ureña/San Cristóbal en Venezuela (Departamento Norte de Santander y Estado de Táchira). Esta región transfronteriza (analizada por Valero, 2008) ha sostenido históricamente intensas relaciones comerciales, demográficas y culturales. No obstante, en la práctica, tuvo un tortuoso proceso de incubación (descrito por Linares, 2005, y por Aparicio y colaboradores, 2016) hasta sucumbir definitivamente ante la situación desfavorable de las relaciones binacionales. Y es que, según Ramírez (2008), nunca existió una perspectiva multinivel, sino un solapamiento disfuncional de niveles diferentes con visiones no coincidentes, lo que abortó la capacidad para construir una visión y unos intereses comunes frente al desarrollo y la integración fronteriza o para formular proyectos conjuntos de mediano y largo plazo. Con frecuencia, anotaba Ramírez (2008), “(...) las proclamas de ser los más integracionistas se elevan ante la necesidad de negociar con sus respectivas capitales, pero desaparecen cuando se trata de compartir recursos con sus vecinos y dejar las ventajas nacionales" (p. 164).

Los proyectos integracionistas centroamericanos han sido consecuentes en mostrar una voluntad de concertación transfronteriza, lo cual se relaciona con una historia de largo plazo de la región. Desde 1976 los países del istmo adoptaron un plan al respecto (bajo el patrocinio del BID) y desde entonces no han faltado planes, programas y proyectos, regionales o binacionales, que han aspirado a producir institucionalidades transfronterizas, pero, como ha anotado Matul (2012), se ha tratado de

experiencias piloto o de corta duración [y] no se ha logrado consolidar una estructura que dé continuidad de lo piloto a lo institucional. Es posible concluir que, hasta ahora, la gestión institucional de los esfuerzos de colaboración en fronteras ha sido tomada a la ligera o no ha merecido una atención adecuada. (p. 71)

Posiblemente la experiencia que ha conseguido mayores éxitos ha sido un proyecto localizado en un área de 7.5 mil kilómetros cuadrados, con 700000 habitantes, que abriga la convergencia de los límites de Honduras, El Salvador y Guatemala, denominado Plan Trifinio. Nació en 1986 al calor de la Organización de Estados Americanos, y su objetivo priorizado era conseguir el desarrollo sostenible de una región muy deprimida a partir de los programas integracionistas del Sistema de Integración Centro Americano (SICA). El plan contaba con una institucionalidad compleja que comenzaba en una comisión tripartita de altos funcionarios de los gobiernos centrales involucrados, e iba descendiendo en la forma de secretarías y unidades técnicas, donde el involucramiento de los actores locales - gobiernos y sociedad civil- era un dato secundario. Ello, de acuerdo con Rhi-Sausi y colaboradores (2011), era una falencia grave que lastraba la autonomía de los espacios en los que debería producirse una auténtica relación transfronteriza. En otras palabras, el Plan Trifinio resulta una pieza poco usual por su altura de miras y sus éxitos en cuanto a un proyecto de desarrollo 
regional de carácter trinacional. Pero es indudable que estos éxitos son menores cuando se trata de evaluarlo como una experiencia de concertación transfronteriza.

\section{Experiencias de concertaciones transfronteriza provenientes de acuerdos binacionales de gobernabilidad de fronteras}

Estas experiencias han tenido numerosas expresiones en el continente, regularmente en interacciones utilitarias de coordinación (Payan, 2010). En algunos casos han sido experiencias locales con agendas muy concretas, posteriormente agregadas a proyectos mayores. Es el caso, para poner un ejemplo, de la Autoridad Autónoma del Lago Titicaca (Meza, 2011), cuya finalidad ha sido el manejo de los recursos hídricos relacionados con el lago, pero que incluye poblados diversos que han sostenido históricamente relaciones tradicionales. Dos de estos poblados denominados ambos Desaguadero y sobre el río del mismo nombre, han sostenido diversas relaciones de intercambio y cooperación en un plano parroquial, lo que ha sido estudiado por Sánchez (2019).

Pero probablemente los casos más ilustrativos son los llamados Comités de Fronteras, creados inicialmente en los años de 1980 en el borde paraguayo/ brasilero y que en la actualidad existen a lo largo de los bordes del cono sur hasta una cantidad de 35 (Chiani, 2019). De acuerdo con Valenciano (1990), en una evaluación temprana, los comités de fronteras eran mecanismos internacionales “(...) cuya función principal es resolver o bien encauzar para su decisión a otros niveles de decisión, ya sea nacionales, provinciales o departamentales, asuntos de diverso contenido referidos a la relación fronteriza en sus distintas manifestaciones" (p. 42). Según Colacrai (2016) estos comités han sido mecanismos importantes para introducir los temas locales en las agendas binacionales, lo cual ella ha estudiado extensamente en la frontera chileno/argentina.

Desafortunadamente no existe una evaluación in situ de estas instituciones. A partir de los estudios parciales (Colacrai, 2016; Dilla \& Álvarez, 2018; Chiani, 2019; Álvarez, 2019) es posible intuir que los comités de fronteras han seguido evoluciones diferentes al calor de dos variables: la relación binacional existente y la propia intensidad y naturaleza de relaciones y flujos transfronterizos. Ello explica - circunscribiéndonos al caso chileno- que el comité Bolivia/Chile sea una entidad de muy poca actividad y limitada a coordinaciones puntuales estatales, o que los comités a lo largo de la frontera argentina/chilena hayan funcionado regularmente como los describe Colacrai (2016) en un contexto de relaciones binacionales fluidas, zonas poco pobladas y relaciones marcadas por prácticas consuetudinarias.

Esta situación cambia en la frontera con Perú, donde existe el complejo urbano transfronterizo Tacna/Arica, y que implica unos siete millones de cruces anuales y una intensa actividad transfronteriza (Dilla \& Álvarez, 2018). En consecuencia, aquí el comité evolucionó hacia temas más amplios relacionados con el desarrollo y la relación social transfronteriza, incluyó a otros actores no estatales y reorganizó su trabajo en varias comisiones que abordaban desde los temas tradicionales del control fronterizo hasta otros de índoles cultural y social. Y en 2012 adoptó el nombre más ambicioso de Comités de Integración y Desarrollo Fronterizo (CIDF).

En un estudio que revisó la interacción desde diversos sectores, en particular desde el sector empresarial, Álvarez (2019) evaluaba positivamente la experiencia “(...) el 
CIDF constituye un espacio político-social de concertación transfronteriza en el que el mundo social ve la oportunidad de transformar y acercar la alta política exterior de los Estados nacionales al territorio fronterizo" (p. 64), pero al mismo tiempo observaba sus numerosos déficits, unos provenientes de la inercia de los sectores sociales involucrados, y otros del propio diseño del mecanismo como partes de dos estados que mantienen sus cosmovisiones nacionalistas. Al recurrir a la tipología de Blatter (2003), se trataría de una "comisión" que coexiste con formas de concertación más avanzadas como las "coaliciones" transfronterizas de la sociedad civil, pero sin alterar en lo fundamental su funcionamiento.

Por consiguiente, habría que reconocer que los CIDF han contribuido a la solución de problemas técnicos en el manejo del límite, a la generación de conocimientos y confianza mutuos entre los actores fronterizos y ha servido de plataforma para generar coordinaciones de actores sobre temas diversos. Pero no ha conseguido afrontar los temas candentes de la relación transfronteriza como las estructuras de gobernanza, que giran en torno al uso irregular de la fuerza de trabajo peruana en la economía ariqueña, a la proliferación de un comercio hormiga reprimido pero vital para la sobrevivencia de cientos de familias de ambos lados y para el consumo popular o a las dificultades nacionalistas que impiden una relación inversionista más activa entre los grupos empresariales de ambos lados.

\section{A modo de conclusiones}

La emergencia de un campo de estudios sobre las concertaciones transfronterizas en América Latina es un rasgo positivo en favor de la construcción de una teoría crítica de las fronteras latinoamericanas. Estos estudios han conseguido rebasar aspectos tradicionales de la geopolítica que habían primado usualmente en el tema e incorporar a sus análisis el accionar de una variedad mayor de actores y situaciones que lo que podían ofrecer los estudios precedentes anclados en visiones centralistas. Su evolución hacia una comunidad epistémica capaz de incidir en las tomas de decisiones públicas sería un momento particularmente feliz que debemos celebrar desde un oficio que solo ocasionalmente consigue ser oído más allá de las parcelas profesionales especializadas.

Nuestra posición crítica sobre el tema, explicada en este artículo, radica en que una parte muy significativa de los estudios realizados sobre el tema —diríamos que su corriente principal - ha prescindido del análisis de la propia realidad continental y de una revisión crítica del stock de estudios acumulados. Esto ha impregnado los estudios sobre concertaciones transfronterizas en nuestro continente de fuertes sesgos europeístas y norteamericanos, que han impedido una contribución heurística más efectiva al debate latinoamericano acerca de la naturaleza de los procesos de fronterización neoliberal en el continente. Si queremos avanzar en esta construcción teórica es imprescindible dialogar con estos potentes (y diversos) referentes intelectuales, pero ello no debe conducir a una aplicación acrítica, y a considerar nuestra realidad como imperfecta en la medida en que se aleje de la realidad noratlántica, y perfectible según la aproximemos a ella.

Pudiera afirmarse que las modalidades de fronterización que ocurren a nivel planetario son, en última instancia, la expresión de la manera como el capitalismo neoliberal toma en cuenta las realidades culturales y políticas de cada región 
transfronteriza, y eventualmente las parasita, incrementando sus réditos desde el intercambio desigual y el aprovechamiento de las ganancias diferenciales. Al mismo tiempo, desde estos territorios — desde los diferentes niveles estatales y desde las comunidades y sus prácticas sociales- se generan procesos de resistencia y/o acomodamiento a la determinación de la economía neoliberal. En términos generales, esto produce un tipo de frontera que ha rebasado en lo fundamental los viejos dilemas contacto/separación, para asumir funciones más relevantes en el control, filtrado y disciplinarización de los factores que cruzan las fronteras. América Latina no es excepción, solo que aquí - a diferencia de Europa con su proyecto político supranacional o de Norteamérica con sus potentes estrategias de acumulaciónpredomina un tipo de frontera marcada por la informalidad, las políticas fuertemente nacionalistas y los pactos integracionistas omisos.

Desde esta realidad se han generado experiencias muy disímiles de concertaciones, algunas de las cuales se han revisado aquí, solo para mostrar que ellas indican un acumulado de algunos logros y muchas frustraciones que ni siquiera consiguen alcanzar los niveles de la relación transfronteriza entre México y Estados Unidos. Cualquiera de las experiencias analizadas en este artículo muestra que el entorno posnacionalista europeo, incluso el menos sonriente escenario norteamericano de grandes estrategias de acumulación que obligan a eliminar factores de incertidumbre, no son afines a una realidad latinoamericana. Los estudios y metodologías desarrollados en estos lugares son, sin lugar a duda, referencias para análisis comparados, pero difícilmente podamos encontrar en ellos un marco teórico común más allá de algunas generalidades.

Para seguir avanzando en estos estudios se necesita una revisión sistemática de las experiencias empíricas y producir un orden taxonómico flexible que permita contrastarlas. En este artículo se intenta preliminarmente este orden a partir de la identificación de la raíz institucional/escalar de los proyectos - locales, estatales nacionales, pactos integracionistas- pero esta taxonomía dista de ser la única, ni siquiera la más relevante. Un análisis de las agendas de estos proyectos, por ejemplo, sugeriría nuevas aristas de evaluación, así como conocer las formas de relacionamientos de las concertaciones formales con la miríada de contactos que se realizan desde la sociedad civil y desde las prácticas sociales de las comunidades. En un contexto continental en que las fronteras son cada vez más femeninas, ninguna aproximación sería exitosa si no asume esta perspectiva de género. No menos relevantes deben ser las aproximaciones al valor de las relaciones consuetudinarias, que en ocasiones se apoyan en identidades ancestrales resurgentes. En pocas palabras, toda una gama de situaciones que espera la paciente labor de la academia.

\section{Agradecimientos}

Este artículo fue realizado con el apoyo del proyecto Fondecyt/ANID 1190133, "La intermediación urbano-portuaria en un contexto transfronterizo: Arica (2008-2018)". 


\section{Referencias}

Agnew, J. \& Oslender, U. (2010). Territorialidades superpuestas, soberanías en disputa: lección empírica desde América Latina. Tabula Rasa, 13, 191-213. http:// www.scielo.org.co/pdf/tara/n13/n13a08.pdf

Alegría, T. (2008). ¿Existen las metrópolis transfronterizas? El caso de Tijuana/San Diego. En H. Dilla (Coord.), Ciudades en la frontera. Aproximaciones críticas a los complejos urbanos transfronterizos (pp. 127-167). Editora Manatí.

Álvarez, C. (2019). Comité de Integración y Desarrollo Fronterizo Perú-Chile: aproximaciones al mundo social y empresarial en torno a la frontera. Si Somos Americanos. Revista de Estudios Transfronterizos, 19(2), 49-67. http://dx.doi. org/10.4067/S0719-09482019000200049

Alvarez, R. (1995). The Mexican-us border: The making of an anthropology of borderlands. Annual Review of Anthropology, 24, 447-470. https://doi.org/10.1146/ annurev.an.24.100195.002311

Anzaldúa, G. (1999). Borderlans/La Frontera. Capitán Swing.

Aparicio, C., Rodríguez, K. \& Pamela, T. (2016). Descripción y contextualización de la política de fronteras. En A. Molano (Comp.), Las fronteras en Colombia como zonas estratégicas: análisis y perspectivas (pp. 17-32). Instituto de Ciencia Política Hernán Echavarría Olózaga. https://biblio.flacsoandes.edu.ec/libros/digital/55098.pdf

Aranda, G. \& Salinas, S. (2017). Paradiplomacia aymara: Empoderamiento en la frontera. Estudios Fronterizos, 18(35), 90-106. https://doi.org/10.21670/ref.2017.35. a05

Barajas, M. (2015). Procesos de integración y cooperación de las diversas organizaciones y actores en la región transfronteriza entre México y Estados Unidos. En M. Barajas, P. Wong-González \& N. Oddone (Coords.), Fronteras y procesos de integración regional. Estudios comparados entre América y Europa (pp. 171-198). El Colegio de la Frontera Norte/Centro de Investigación en Alimentación y Desarrollo/Juan Pablos Editor.

Barajas, M., Wong-González, P. \& Oddone, N. (Eds.). (2015). Fronteras y procesos de integración regional. Estudios comparados entre América y Europa (pp. 171-198). El Colegio de la Frontera Norte/Centro de Investigación en Alimentación y Desarrollo/Juan Pablos Editor.

Batista da Silva, L. (2013). Redes de transporte de mercadorias e fronteira: a logística nas cidades gêmeas de Corumbá (Brasil) e Porto Suárez (Bolívia). Revista transporte y territorio, 9, 141-160.

Blatter, J. (2003). Debordering the world of states. En N. Brenner, B. Jessop, M. Jones \& G. Mcleod (Eds.), State/Space: A reader (pp. 185-206). Wiley-Blackwell Publishing.

Cerrarols, R., Schmidt di Friedberg, M. \& Neve, M. (2018). Claude Raffestin. Territorio, frontera, poder. Icaria.

Chiani, A. M. (2019). ¿Qué rol cumplen los comités de integración en el proceso de integración regional? XVII Congresso Internacional Fórum Universitário Mercosul, América Latina: Resgatar a Democracia. Repensar a Integração. Foz de Iguazú. 
Colacrai, M. (2016). Cuando la frontera dialoga: Singularidades de la relación argentino-chilena en las últimas décadas. Estudios Fronterizos, 17(34), 85-99, http:// dx.doi.org/10.21670/ref.2016.34.a05

Comunidad Andina de Naciones (CAN). (2001). Decisión 501: Zonas de Integración Fronteriza (ZIF). http:/ / www.comunidadandina.org/Seccion.aspx?id=122\&tipo=TE

Dear, M. \& Leclerc, G. (2003). Postborder City: Cultural Spaces of Bajalta California. Routledge.

Dilla, H. (2016). La regionalización precaria en la frontera dominico/haitiana. Si somos americanos, 16(1), 15-41.http://dx.doi.org/10.4067/S0719-09482016000100002

Dilla, H. \& Álvarez, C. (2018). La vuelta de todo eso: economía y sociedad en la frontera chileno/peruana: el complejo urbano transfronterizo Tacna/Arica. Ril Editores.

Dilla, H., Cabezas, F. \& Figueroa, M. (2020). Notes for a discussion on Latin American cross-border regions. Journal of Borderlands Studies, 1-17. https://doi.org/10.108 $0 / 08865655.2020 .1784033$

Dilla, H. \& Hansen, K. (2019). El gobierno de las territorialidades transfronterizas internacionales: la experiencia latinoamericana. Geopolitica(s), 10(2), 259-279. https://doi.org/10.5209/geop.61580

Domínguez, A. R. (2010). La organización de las fronteras: etnografía de la cotidianidad fronteriza Chui/Chuy. En C. Casas \& M. Ortolán (Eds.), Miradas comparativas sobre las fronteras en América Latina. Miguel Ángel Porrúa.

Dorfman, A. (2020). Geografía moral del contrabando: una mirada desde las fronteras meridionales de Brasil. En H. Dilla \& F. Neira (Eds.). Donde el pedernal choca con el acero. Hacia una teoría crítica de las fronteras latinoamericanas (pp. 155-174). Ril editores.

Fuentes, C. \& Peña, S. (2010). Globalization and its effects on the urban socio-spatial structure of a transfrontier metropolis: El Paso, TX-Ciudad Juárez, Chih-Sunland Park, NM. En K. Staudt, C. Fuentes \& J. Monárrez (Eds.). Cities and citizenship at the us-Mexico border (pp. 93-118). Palgrave.

Ganster, P. \& Collins, K. (2017). Binational cooperation and twinning: A view from the us-Mexican border, San Diego, California, and Tijuana, Baja California, Journal of Borderlands Studies, 32(4), 497-511. https://doi.org/10.1080/08865655.2016. 1198582

Gerber, J. \& Anderson, J. (2015). Twenty years of nAFTA: Are measures of human development converging on the border? En M. Barajas, P. Wong-González \& N. Oddone (Eds.) Fronteras y procesos de integración regional. Estudios comparados entre América y Europa (pp. 133-150). El Colegio de la Frontera Norte/Centro de Investigación en Alimentación y Desarrollo/Juan Pablos Editor.

Giménez, V. (2010). Movilidades y escalas de la acción política. En V. Giménez \& S. Montenegro (Eds.), La triple frontera: dinámicas culturales y procesos transnacionales. Espacio Editorial.

González, S. (2019). La frontera como margen heterológico. El tripartito andino (Bolivia, Perú y Chile) y el espejismo académico sobre los "Aymaras sin fronteras". Diálogo andino, 60, 115-125. http://dx.doi.org/10.4067/S071926812019000300115

González, S., Cornago, N. \& Ovando, C. (2016). Relaciones transfronterizas y paradiplomacia en América Latina. Aspectos teóricos y estudio de casos. Ril Editores. 
Grimson, A. (2000). ¿Fronteras políticas vs. fronteras culturales? En A. Grimson (Comp.), Fronteras naciones e identidades. La periferia como centro (pp. 9-49). Ciccus.

Haas, P. M. (1992). Introduction: Epistemic communities and international policy coordination, International Organization, 46(1), 1-35. https://www.jstor.org/stable/2706951

Harvey, D. (2014). Espacios del capital. Hacia una geografía crítica. Akal.

Herzog, L. (1990). Where North meets South: cities, space and politics on the United Satates-Mexico border. University of Texas Press.

Heyman, J. (2010). us-Mexico border cultures and the challenge of asymmetrical interpenetration. En H. Donnan \& T. Wilson (Eds.), Borderlands. University Press of America. https://www.academia.edu/5834241/Heyman_Josiah_McC_US_ Mexico_Border_Cultures_and_the_Challenge_of_Asymmetrical_Interpenetration_download_available_

Hobsbawn, E. (2015). Naciones y nacionalismo desde 1780. Crítica.

Jaquet, H. (2008). Más allá de la frontera, las fronteras. En H. Dilla (Coord.), Ciudades en la frontera. Aproximaciones críticas a los complejos urbanos transfronterizos. Editora Manatí.

Kearney, M. (2008). La doble misión de las fronteras como clasificadoras y como filtros de valor. En L. Velazco (Ed.), Migración, fronteras e identidades étnicas transnacionales (79-110). Miguel Angel Porrúa.

Leresche, J. P. \& Saez, G. (2002). Political frontiers regimes: Towards cross-border governance? En M. Perkman \& N. L. Sum (Eds.), Globalization, regionalization and cross border regions (pp. 77-98). Palgrave McMillan.

Linares, R. (2005). Zona de integración fronteriza y su dimensión territorial en la frontera Táchira (Venezuela)-Norte de Santander (Colombia). Aldea Mundo, 19, 45-54.

Martínez, O. (1994). Border people: Life and society in the us-Mexico borderland. The University of Arizona Press.

Massi, F. \& Falabella, G. (2005). Desarrollo económico regional en la frontera Paraguai-Brasil: estudio exploratorio del Alto Paraná. En T. Machado de Olivera (Org.), Territorio sem limites (pp. 307-347). Editorial ufMs.

Matul, D. (2012). Vecindad, cooperación y confianza mutua: una revisión de las prácticas en las fronteras de Centroamérica. En S. Moya (Ed.), Las fronteras: espacios de encuentro y cooperación (pp. 65-80). Flacso.

Mendoza, J. E. \& Dupeyron, B. (2020). Economic Integration, Emerging Fields and Cross-border Governance: The Case of San Diego-Tijuana. Journal of Borderlands Studies, 35(1), 55-74. https://doi.org/10.1080/08865655.2017.1367711

Meza, N. (2011). Espacios regionales fronterizos. Integración, más allá del discurso político. Palibrio.

Mezzadra, S. \& Neilson, B. (2013). Border as method or the multiplication of labor. Duke University Press.

Molano, A. (Ed.). (2016). Fronteras en Colombia como zonas estratégicas: análisis y perspectivas. Instituto de Ciencia Política Hernán Echavarría Olózaga y Konrad Adrenauer en Colombia.

Molano, G. (2007). El interregionalismo y sus límites. Estudios Internacionales, 40(158), 9-27. https://revistaei.uchile.cl/index.php/REI/article/view/14089 
Morín, E. (2000). Sociología. Editorial Tecnos.

Moya, S. (Ed.). (2012). Las fronteras: espacios de encuentro y cooperación. Flacso.

Nogueira, R. (2008). Tabatinga: una ciudad en la frontera de la Amazonía. En H. Dilla (Coord.), Ciudades en la frontera. Aproximaciones críticas a los complejos urbanos transfronterizos (pp. 97-126). Editorial Manatí.

Oddone, N., Quiroga, M., Sartori, H. \& Williner, A. (2016). Pactos territoriales en la construcción de regiones transfronterizas: por una mayor integración a múltiples niveles. Cepal. https://www.cepal.org/sites/default/files/publication/files/40606/ S1600246_es.pdf

Oddone, N. \& Matiuzzi, G. (2017). Cross-border paradiplomacy in Mercosur: a critical overview. Monções: Revista de Relações Internacionais da UFGDV, 6(12), 199-216.

Oddone, N. \& Ramos, J. M. (Eds.). (2018a). Integración y paradiplomacia transfronteriza: experiencias comparadas del Río Bravo hasta la Patagonia (tomo I). Colef.

Oddone, N. \& Ramos, J. M. (Eds.). (2018b). Integración y paradiplomacia transfronteriza: experiencias comparadas del Río Bravo hasta la Patagonia (tomo II). Colef.

Oliveras, X., Durà, A. \& Perkman, M. (2010). Las regiones transfronterizas: balance de la regionalización de la cooperación transfronteriza en Europa (1958-2007). Documents d'análisi geográfica, 56(1), 21-40. https://dialnet.unirioja.es/servlet/ articulo?codigo=3243489

Ovando, C., Álvarez, G. \& López, S. (2020). La visión geopolítica del Estado de Chile hacia la proyección fronteriza del Norte Grande: algunas lecturas críticas. Geopolítica(s). Revista de estudios sobre espacio y poder, 11(1), 39-70. https://doi. org/10.5209/geop.61452

Paikin, D. (2012). Integración productiva, territorio y fronteras en el Mercosur. Cuadernos sobre Relaciones Internacionales, Regionalismo y Desarrollo, 7(13), 105-122.

Payan, T. (2010). Crossborder governance in a tristate, binational region. En K. Staudt, C. Fuentes \& J. Monárrez (Eds.), Cities and citizenship at the Us-Mexico border (pp. 217-242). Palgrave.

Perkmann, M. (2002). Euroregions: institutional entrepreneurship in the European Union. En M. Perkman \& N. L. Sum (Eds.), Globalization, regionalization and cross border regions (pp. 103-124). Palgrave McMillan.

Prescott, J. R. V. (2015). Political frontiers and boundaries. Routledge.

Ramírez, S. (2008). Las zonas de integración fronteriza de la Comunidad Andina. Comparación de sus alcances. Estudios Politicos, 32, 135-169. https://www.redalyc.org/pdf/164/16429060005.pdf

Rhi-Sausi, J. L. \& Conato, D. (2009). Fronteras y cooperación transfronteriza en América Latina: introducción al Proyecto Fronteras Abiertas. En J. L. Rhi-Sausi \& D. Conato (Coord.), Cooperación transfronteriza e integración en América Latina (pp. 11-31). https://www.cespi.it/en/ricerche/cooperacion-transfronteriza-e-integracion-en-america-latina

Rhi-Sausi, J. L., Conato, D., Oddone, N. \& Salerno, D. (2011). Conceptualización de la cooperación fronteriza en el Sistema de la Integración Centroamericana. Ces$\mathrm{pi} /$ Sica.

Rhi-Sausi, J. L. \& Oddone, N. (2013). Integración regional y cooperación transfronteriza en los nuevos escenarios de América Latina. Investigación Ẽ Desarrollo, 21(1), 260-285. 
Rouvière, L. (2008). ¿Un territorio político transfronterizo? Formas de legitimación de una experiencia de acción política intermunicipal entre Bolivia, Chile y Perú (вСР). Si somos Americanos, Revista de Estudios Transfronterizos, 9(2), 13-29.

Rouvière, L. (2014). Gobernar territorialidades transfronterizas. seguridad y "desarrollo con identidad" aymara en la triple frontera del norte de Chile (Chile-Perú-Bolivia). Trace, (65), 37-50. http://www.scielo.org.mx/scielo.php?pid=S0185-6286 2014000100004\&script=sci_abstract\&tlng=es

Sánchez, F. (2015). Comunidad Andina: ¿puede hablarse de política regional? Aldea Mundo, 20(40), 86-95. https://www.redalyc.org/pdf/543/54346387008.pdf

Sánchez, R. (2019). Territorios transfronterizos. Plural.

Scott, J. (2002). On the political economy of cross-border regionalism: regional development and cooperation on the us-Mexican border. En M. Perkman \& N. L. Sum (Eds.). Globalization, regionalization and cross border regions (pp. 191-211). Palgrave McMillan.

Sohn, C. (2014). Modelling cross-border integration: The role of borders as a resource. Geopolitics, 19(3), 587-608. https://doi.org/10.1080/14650045.2014.913029

Sohn, C. (2018). Cross-border regions. En A. Paasi, J. Harrison \& M. Jones (Eds.), Handbook on the geographies of regions and territories (pp. 290-310). Edward Elgar Publishing.

Soja, E. (2005). Borders unbound: globalization, regionalism, and the postmetropolitan transition. En H. V. Houtum, O. Kramsch \& W. Zierhofer (Eds.), Bordering space (pp. 33-46). Ashgate.

Soldatos, P. (1993). Cascading subnational paradiplomacy in an interdependent and transnational world. En D. Brown \& E. Fry (Eds.), State and provinces in the international economy, (pp. 45-64). Institute of Governmental Studies. https:// www.queensu.ca/iigr/sites/webpublish.queensu.ca.iigrwww/files/files/pub/ archive/books/Statesandprovince-brownfry1993.pdf

Soto, W. \& Ramírez, J. C. (2014). Territorios y espacios transfronterizos: una visión desde Centroamérica. Universidad Nacional Costa Rica.

Tilly, C. (1990). Coerción, capital y los estados europeos (990-1990). Alianza Editorial.

Van Houtum, H. \& Van Naerssen, T. (2005). Bordering, ordering and othering. En H. van Houtum, O. Kramsch \& W. Zierhofer (Eds.), Bordering space (pp. 125-136). Ashgate.

Valenciano, E. (1990). Los comités de frontera: funcionamiento y experiencia. Identificación, preparación y evaluación de proyectos de integración fronteriza. INTAL.

Valero, M. (2008). Ciudades transfronterizas e interdependencia comercial en la frontera Venezuela/Colombia. En H. Dilla (Coord.), Ciudades en la frontera. Aproximaciones críticas a los complejos urbanos transfronterizos (pp. 69-95). Editorial Manatí.

Vila, P. (2003). Processes of identification on the U.s.-Mexico border. The Social Science Journal, 40(4), 607-625. https://doi.org/10.1016/S0362-3319(03)00072-7

Zárate, C., Aponte, J. \& Victorino, N. (2017). Perfil de una región transfronteriza en la Amazonia. La posible integración de las políticas de frontera de Brasil, Colombia y Perú. Editorial Universidad Nacional de Colombia. 
Haroldo Dilla Alfonso

Cubano/dominicano. Sociólogo e historiador, con residencia actual en Chile. Doctor de la Ecole Polytechnique Fédérale de Lausanne, Suiza. Profesor e investigador titular del Instituto de Estudios Internacionales (Inte) de la Universidad Arturo Prat (Chile). Líneas de investigación: estudios fronterizos y sociología urbana. Publicación reciente: Dilla, H. \& Neira, F. (Eds.). (2020). Donde el Pedernal choca con el Acero. Ril Editores.

Camila Contreras Vera

Chilena. Cientista política de la Pontificia Universidad Católica de Chile. Máster en gobernanza y desarrollo de la Universidad de Amberes, Bélgica. Actualmente es asistente de investigación en el Instituto de Estudios Internacionales (Inte) de la Universidad Arturo Prat (Chile). Líneas de investigación: fronteras, migración, multiculturalismo y religión. Publicación reciente: Dilla, H. \& Contreras, C. (2020). Flujos comerciales agroalimentarios en una región transfronteriza dominico/ haitiana: Elías Piña/Departamento Central. Si Somos Americanos. Revista de Estudios Transfronterizos, 20(1), 8-32. 